\title{
Performance of WVSS-II hygrometers on the FAAM research aircraft
}

\author{
A. K. Vance ${ }^{1}$, S. J. Abel ${ }^{1}$, R. J. Cotton ${ }^{1}$, and A. M. Woolley ${ }^{2}$ \\ ${ }^{1}$ Met Office, Exeter, UK \\ ${ }^{2}$ FAAM, Cranfield, UK \\ Correspondence to: A. K. Vance (alan.vance@metoffice.gov.uk) \\ Received: 2 May 2014 - Published in Atmos. Meas. Tech. Discuss.: 19 August 2014 \\ Revised: 8 December 2014 - Accepted: 16 December 2014 - Published: 28 March 2015
}

\begin{abstract}
We compare the performance of five hygrometers fitted to the Facility for Airborne Atmospheric Measurement's (FAAM) BAe 146-301 research aircraft using data from approximately 100 flights executed over the course of 2 years under a wide range of conditions. Bulk comparison of cloud free data show good agreement between chilled mirror hygrometers and a WVSS-II fed from a modified Rosemount inlet, but that a WVSS-II fed from the standard flush inlet appears to over-read compared to the other instruments, except at higher humidities.

Statistical assessment of hygrometer performance in cloudy conditions is problematic due to the variable nature of clouds, so a number of case studies are used instead to investigate the performance of the hygrometers in sub-optimal conditions. It is found that the flush inlet is not susceptible to either liquid or solid water but that the Rosemount inlet has a significant susceptibility to liquid water and may also be susceptible to ice. In all conditions the WVSS-II responds much more rapidly than the chilled mirror devices, with the flush inlet-fed WVSS-II being more rapid than that connected to the Rosemount.
\end{abstract}

\section{Introduction}

Water vapour is well established as the most important greenhouse gas and, hence, is crucially important in determining the radiation budget of the atmosphere. Its vertical distribution has a significant impact on local radiative heating and cooling, and on the net fluxes at the surface and at the top of the atmosphere. Its three-dimensional distribution has a large impact on the dynamics and thermodynamics of the at- mosphere as well as controlling the distribution of clouds. A thorough understanding of the distribution of water vapour is, therefore, critically important to our understanding and monitoring of climate change, to improve forecasts from operational numerical weather prediction (NWP) and to better interpret data from current and future satellite instruments.

Meteorological observations from commercial aircraft have been an important part of the global observing system for some time, making a demonstrable positive impact on the output of both NWP models and human forecasters (Moninger et al., 2006; Petersen et al., 2010) as well as to the aviation industry (Baker et al., 2011). Aircraft routinely provide air temperature and derived wind speed \& direction data via the World Meteorological Organization's (WMO) Aircraft Meteorological Data Relay (AMDAR) programme (WMO, 2014a). AMDAR allows for the inclusion of humidity data, and such observations have been included for well over a decade, but only around 100 aircraft currently report humidity operationally, mostly in the USA. A contributing factor to this may be that the only sensor to meet the requirements of AMDAR, currently, is the Water Vapour Sensing System version two (WVSS-II) (WMO, 2014a).

No peer reviewed literature exists assessing the performance of the WVSS-II and, although numerous unpublished items reporting intercomparison results may be found (e.g. Mamrosh et al., 2006; Baker et al., 2011; Bedka et al., 2006; Hoff, 2010), these are of limited use for the purposes of atmospheric research. In the main, the WVSS-II has been compared to radiosondes launched at, or close to, an airfield attended by commercial aircraft fitted with a WVSS-II, and the emphasis is on the boundary layer and lower free troposphere. This is a valuable exercise in assessing the util- 
ity of such routine AMDAR measurements as an adjunct to, or as a replacement for, radiosonde observations for NWP purposes, and positive impacts on forecasts have been reported (Moninger et al., 2006; WMO, 2014b). These studies have two serious limitations: (1) a radiosonde and an aircraft cannot be guaranteed to sample the same air mass throughout their ascents, which increases the uncertainty, and (2) the WVSS-II measurements in question are truncated for transmission (two-digit mantissa, one digit exponent) which "can add substantial error to the moisture reports exceeding $10 \mathrm{k} / \mathrm{kg}$ " (Bedka et al., 2006). These shortcomings are avoided in this study as all humidity data were recorded simultaneously on the same aircraft and all WVSS-II data were recorded at higher resolution via the WVSS-II's diagnostic/research output.

In 2010, Deutscher Wetterdienst (DWD) provided the Met Office with two WVSS-II units to be trialled on the FAAM aircraft as part of the EUMETNET AMDAR (E-AMDAR) programme. These have been operated semi-routinely alongside the existing two chilled mirror hygrometers. Here we present data collected on an opportunistic basis during approximately 100 flights of the FAAM aircraft, which took place between 22 February 2011 and 23 September 2013. The flights were mainly conducted around the United Kingdom but data are included from various experiments at locations ranging from the western Sahara to the Svalbard Islands, as well as from the southern United States and south eastern Canada, encountering a wide range of conditions. Data have been recorded at altitudes up to $11 \mathrm{~km}$ with absolute humidities ranging down from around $13 \mathrm{~g} \mathrm{~m}^{-3}$; the lowest value is not known for reasons that shall be discussed below.

The following section briefly describes the instruments compared in this paper with the treatment of offsets between them described in Sect. 3. Section 4 describes the relative performance of the four hygrometers in cloud free conditions while Sect. 5 presents a number of case studies illustrating the performance of the WVSS-II in cloudy and in rapidly changing conditions.

\section{Instruments and installation}

\subsection{Buck CR-2 (Buck)}

The Buck measures atmospheric dewpoint using the chilled mirror technique. Air is extractively pumped through an aft facing inlet, located $1.8 \mathrm{~m}$ aft of the nose and outside the $99 \%$ free-stream boundary layer, through a heated pipe into a sample chamber and over a mirror-like metal surface. The mirror temperature is regulated using a Stirling-cycle cooler until condensation begins to form on the mirror, this being the dew or frost point. The condensation layer is monitored optically, and the mirror temperature is measured using an embedded platinum resistance thermometer. The Buck is calibrated annually at the National Physical Laboratory in Teddington, UK, and the dewpoint measurement is directly traceable to ITS-90 (FAAM, 2014a). Data from the $2013 \mathrm{cal}-$ ibration show the Buck to be accurate to better than $\pm 0.7 \mathrm{~K}$, for frost points down to $203 \mathrm{~K}$ (approximately $0.002 \mathrm{~g} \mathrm{~m}^{-3}$ at an altitude of $10 \mathrm{~km}$ ).

\subsection{General Eastern 1011B (GE)}

The GE is another thermoelectric chilled mirror dew point/frost point hygrometer, originally fitted to the Met Office C-130 and transferred to the FAAM aircraft in 2004. Its inlet is unheated, located $6 \mathrm{~m}$ aft of the nose and $4 \mathrm{~cm}$ from the skin, leaving it within the boundary layer. The accuracy of the FAAM instrument is given by the manufacturer as $\pm 0.2 \mathrm{~K}$ above $273 \mathrm{~K}$, decreasing to $\pm 1 \mathrm{~K}$ between 233 and $198 \mathrm{~K}$ (General Eastern Instruments, 1987) with a resolution of $0.03 \mathrm{~K}$. The actual performance of the instrument is strongly dependent on the ambient temperature, and data may be subject to an increasing positive bias below around $250 \mathrm{~K}$ (FAAM, 2014b).

\subsection{Total Water Counter (TWC)}

The TWC is a Lyman- $\alpha$ absorption instrument developed by the Met Office for use on its C-130 aircraft and transferred to the FAAM aircraft in 2004. The operating range, accuracy and resolution are quoted as 0 to $20 \mathrm{~g} \mathrm{~kg}^{-1}, \pm 0.15$ and $\pm 0.005 \mathrm{~g} \mathrm{~kg}^{-1}$, respectively (Nicholls et al., 1990) but, in practice, this can be improved upon as the accuracy is primarily determined by the manner in which it is calibrated, and the instrument which it is calibrated against (e.g. Abel et al., 2014; Brown and Francis, 1995). Note that although this instrument will measure the combined amount of water in all phases, it may be regarded as a hygrometer in cloud free air. As the TWC uses magnesium fluoride windows and a Lyman- $\alpha$ source, both of which degrade over time, the instrument must be calibrated on a flight-by-flight basis using one of the chilled mirror instruments (usually the GE) and, therefore, does not provide an independent measurement. For this reason, and because it is not operated on all flights, it has been excluded from the bulk intercomparison. The TWC does, however, have a very short, isokinetic intake resulting in a very rapid response, which makes it ideal for assessment of the response times of other hygrometers on the aircraft.

\subsection{WVSS-II (wvssF, wvssR)}

The WVSS-II (Fleming and May, 2004) uses a near-infrared tunable diode laser absorption spectrometer to measure atmospheric water vapour. The instrument is designed for use on commercial aircraft to support airline operations and government applications, as part of the global AMDAR programme, and regional or national programs implementing the AMDAR objectives (WMO, 2014a). As such, it is intended 


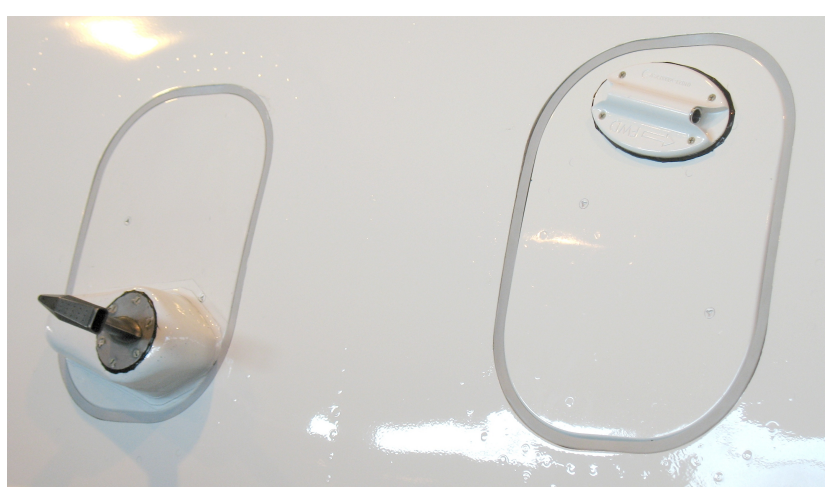

Figure 1. External view of WVSS-II fitted to FAAM aircraft showing the two inlets (Rosemount, left; flush, right) angled down to match the local air flow in flight.

to remain accurate and stable for long periods with minimal maintenance.

The two units fitted to the FAAM aircraft are installed on window blanks on the starboard side of the aircraft forward of the wing. The windows were selected so that the air reaching the inlets should not have passed over the forward door or any other openings in the pressure hull liable to leak cabin air. The substantive difference between the two fitments is in the inlets used: one uses the standard flush inlet ("air sampler") supplied by SpectraSensors and used on commercial aircraft (wvssF) while the other is fed by a modified Rosemount inlet mounted on a short pylon to locate its mouth $12 \mathrm{~cm}$ from the skin (wvssR), which is believed to place it outside the aircraft's boundary layer (data from BAE Systems); the flush inlet is wholly within it (further consideration of siting of wvssR is described in Vance et al., 2011). The installation is shown in Fig. 1. The instruments themselves are identical with the exception that wvssR had the heater of its sample chamber disconnected by DWD prior to its transfer to the Met Office as it was believed that adequate adiabatic heating would arise in the Rosemount inlet to render the sample heater superfluous, and that its disconnection would permit a more uniform temperature field in the cell, and enhance accuracy; the inlet hoses for both units remained heated.

In autumn 2012 wvssF developed a serious problem and was replaced with a new, similarly unmodified, WVSS-II; the inlet and hoses were not changed.

The usable range and accuracy, respectively, are given by the manufacturer as 50-60000 ppmv and \pm 50 ppmv or $\pm 5 \%$ of reading, whichever is greater, but the precise lower limit of the instrument is unclear. During the AquaVIT 2 aircraft hygrometer intercomparison in 2013 at the Karlsruher Institut für Technologie (KIT), wvssF was seen to report absolute humidities down to $0.6 \mathrm{mg} \mathrm{m}^{-3}$ when connected to the Aerosol Interaction and Dynamics in the Atmosphere (AIDA) cloud chamber (then containing $0.1 \mathrm{mg} \mathrm{m}^{-3}$ ) but unpublished, preliminary data from intercomparison with the PhysikalischTechnische Bundesanstalt's (PTB) humidity standard (Thun- der 3900) as part of AquaVIT 2 suggest a lower limit of around $15 \mathrm{mg} \mathrm{m}^{-3}$ (D. Smorgon, personal communication, 2013). It is suspected that the discrepancy was caused by the desorption of water from the walls of the plumbing used to connect wvssF to the humidity standard as this had been open to atmospheric conditions, whereas the plumbing between the instruments and the AIDA chamber had been maintained at a low pressure and low humidity for several days. Previous laboratory work has, however, suggested a lower detection limit of $3.6 \mathrm{mg} \mathrm{m}^{-3}$ (Hoff, 2009) but it should, perhaps, be noted that substantial differences in the performance of some WVSS-II units have been seen in the past (Petersen et al., 2010), and that lower limits seen in laboratory studies are very unlikely to be matched in the field.

As previously noted, the WVSS-II has two data outputs: one uses the ARINC 429 protocol, and is used on conventional AMDAR installations; the other (used on the FAAM aircraft) uses RS232. The RS232 output has significantly better resolution than the ARINC 429 (the limitations of which are discussed in Petersen et al. (2008) and Bedka et al., 2006), and also includes "housekeeping" data.

\section{Offsets}

The offset between pairs of hygrometers during the test period has been calculated in the following way, using only data indicated to be cloud free (liquid water content less than $0.01 \mathrm{~g} \mathrm{~m}^{-3}$ ) according to the cloud droplet probe (CDP) (Lance, 2010). Where the humidities differ by more than a factor of two, the data are rejected, as this generally indicates an instrument malfunction. Data are then selected from periods where the instruments appear to be stable. The criterion used to determine this was that the difference in the absolute rates of change of the two humidities was required to be below a certain threshold value. This criterion does not require the two instruments to be reporting the same values but it does require that they be tracking changes in the atmosphere in the same way, thereby filtering out periods where instrument lag dominates, or where either instrument is not stable. The situation may exist (although it is very rarely seen) where both chilled mirrors are unstable and their mirrors briefly oscillate in phase; to guard against the inclusion of data from such periods the differential rate of change was smoothed using a Gaussian filter with a $30 \mathrm{~s}$ full width at half maximum. The aforementioned limit was then set so as to reject $90 \%$ of the available data. This value, to some extent arbitrary, is a compromise arrived at by inspection, between retaining sufficient data for meaningful comparison and maximising the rejection of poor data. From the remaining data, a median, percentage difference was calculated. This single figure takes no account of any calibration drift that might have occurred during the period over which the data were collected. Although the possibility of drift occurring should be considered, the nature of the flying makes this difficult for 
Table 1. Percentage average offsets between pairs of hygrometers. Where comparison with the new wvssF exists, the value for this is given in parentheses.

\begin{tabular}{ll|rrrr}
\hline \multicolumn{2}{c|}{$\begin{array}{r}\text { test-ref. } \\
\text { ref. }\end{array} \times 100$} & \multicolumn{4}{c}{ Test hygrometer } \\
\cline { 3 - 6 } & & wvssF & wvssR & Buck & GE \\
\hline \multirow{2}{*}{ Reference } & wvssF & & $-1.9(0.33)$ & -4.8 & $-5.2(-0.43)$ \\
hygro. & Buck & $1.9(-0.35)$ & & -0.52 & -2.2 \\
& GE & 5.0 & 0.16 & & -2.1 \\
& $5.2(0.31)$ & 2.0 & 1.3 & \\
\hline
\end{tabular}

a number of reasons. Firstly, simply by the nature of fieldwork, none of the measurements are precisely reproducible. Secondly, most flights occurred as part of specific experiments sometimes lasting several weeks at a time that targeted particular areas and conditions. It is therefore likely that any "drift" calculated would include some element due the differing climatologies, the significance of which cannot readily be quantified but is believed to be substantial. Where data exist, figures are shown for the new wvssF, after the old (in parentheses, Table 1). It should be noted, however, that annual laboratory calibrations of the Buck indicate minimal drift. Comparison to the PTB's Thunder 3900 during AquaVIT 2 suggest that wvssF may under read by around $3 \%$ which, although significant with respect to the comparisons presented here, is well within SpectraSensors' specifications.

\section{Cloud-free comparisons}

Data were selected in the same manner as for the offset assessment, except that in all cases the differential rate of change used was that relating to the two chilled mirror devices (chosen as they are the slowest responding, and least stable, instruments); this ensures that in all cases the data under consideration come from measurements of the same air. As here we are interested in comparing the relative performance of the hygrometers rather than the quality of their absolute calibration, in each case, the single-figure offset (Table 1) has been used to adjust the data; this also permits the inclusion of data from the new wvssF alongside the old. Figures 2-4 show comparisons of the four hygrometers plotted as [instrument 1]-minus-[instrument 2] as a percentage of [instrument 2], versus [instrument 2]. This percentage measure was chosen to facilitate the graphical representation of differences otherwise spanning several decades. In each, boxes are overlaid indicating the median and upper and lower quartiles, with whiskers denoting the 2 nd and 98 th percentiles, of the difference between the instruments (calculated in bins, plotted at bin medians).

It is immediately clear that the criteria used to select data, although strict, do still permit the inclusion of some "bad" data; in the interests of preserving objectivity, however, no attempt to remove these has been made. It is also clear that comparison below $0.02 \mathrm{~g} \mathrm{~m}^{-3}$ is hampered by a lack of good data and that all four hygrometers agree in more humid conditions.

The Buck and wvssR show excellent agreement (within the interquartile range (IQR)) throughout the range of observed humidities, with the median being within $\pm 3 \%$ for most of this range (Fig. 2). Although the Buck CR-2 should be able to measure substantially lower humidities than the WVSS-II, in the past the FAAM Buck has struggled to produce mirror temperatures below $-70^{\circ} \mathrm{C}$ (behaviour also noted at AquaVIT 2 ), which may contribute to the agreement seen here in drier conditions, possibly masking some overreading of the wvssR.

Although the GE and Buck agree to within the IQR throughout most of their range (Fig. 3), the GE exhibits an increasing tendency to over-read below $0.1 \mathrm{~g} \mathrm{~m}^{-3}$, which approximates to a mirror temperature of around $230 \mathrm{~K}$. This is typical of the frost points encountered when the ambient temperature is around $250 \mathrm{~K}$, supporting FAAM's suspicions of a possible positive bias below $250 \mathrm{~K}$ due to desorption of retained water from internal surfaces.

The performance of the wvssF is more problematic (Fig. 4). Although above $1 \mathrm{~g} \mathrm{~m}^{-3}$ wvssF and wvssR agree very well, with an IQR of $1 \%$ at $2 \mathrm{~g} \mathrm{~m}^{-3}$, it is clear that the wvssF reads progressively higher than wvssR as the humidity reduces, with the difference lying outside the IQR for humidities below $0.5 \mathrm{~g} \mathrm{~m}^{-3}$. Since the instruments are fundamentally the same, and measuring the same air mass, the small spread of data might be expected. The substantive difference between the two is in the inlet design; over-reading of the WVSS-II fed from the standard flush inlet has been noted by other groups operating a WVSS-II alongside other hygrometers (A. Hoff and S. Carlberg, personal communications, 2011). It should, however, be borne in mind that because the flush inlet samples air approximately $5 \mathrm{~mm}$ from the skin of the aircraft, the performance of this inlet may vary significantly from depending on the type of aircraft and location on that aircraft (A. Hoff, personal communication, 2011; B. Ford, personal communication, 2012); this has not been investigated here.

\section{Case studies}

In the following case studies, the offsets calculated for the bulk comparison (Sect. 4) and described in Sect. 3, have not been applied.

\subsection{Rapid changes}

Figure 5 shows a time series from flight B668 on 23 January 2012, between Iceland and the Faroes. At this time the aircraft was profiling in and out of a moist, stratocumulustopped boundary layer, with much drier air above. The top panel shows the aircraft altitude, with the grey shading indicating where the aircraft was in cloud (here defined as 


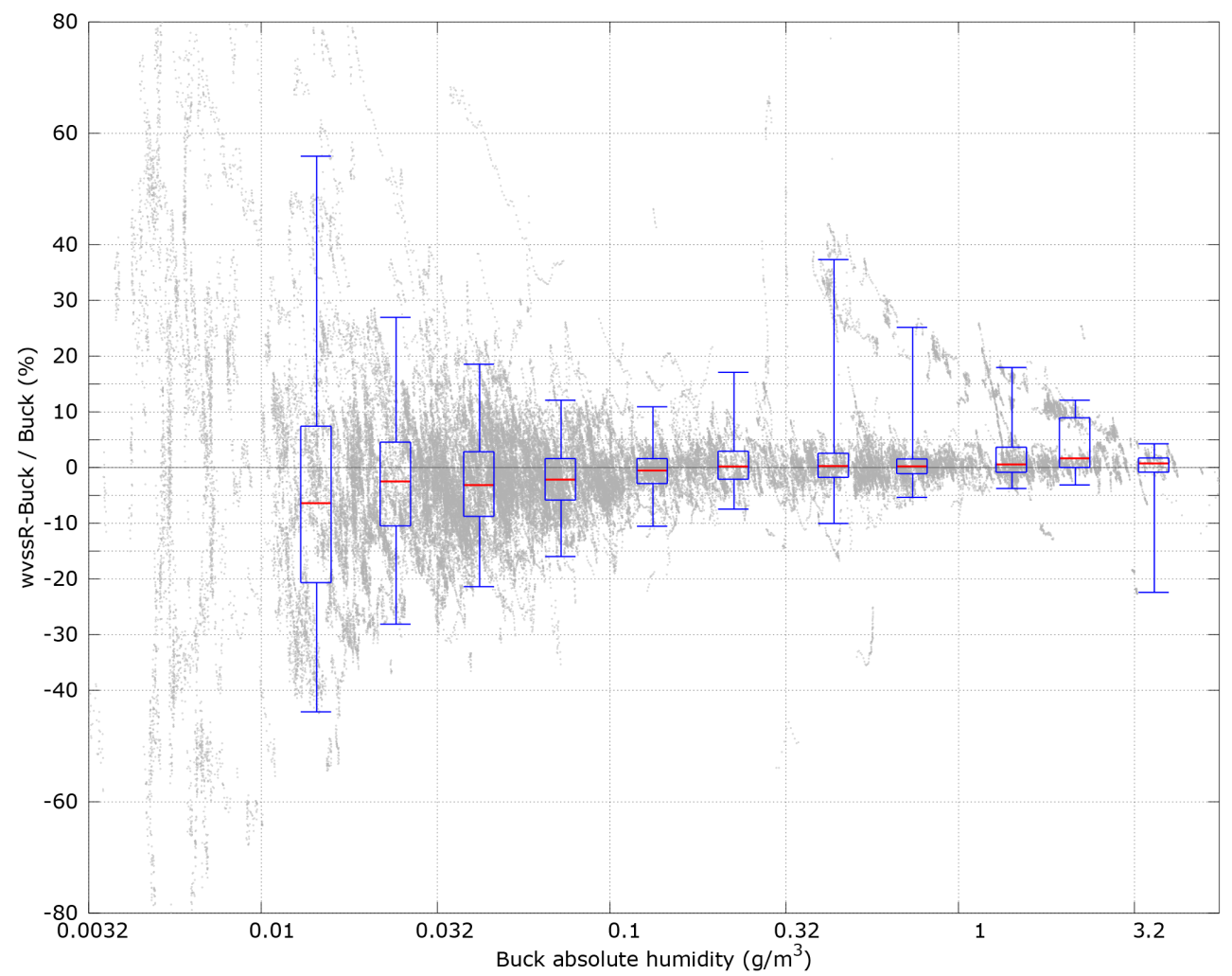

Figure 2. wvssR minus Buck in cloud free conditions. Boxes indicate binned quartiles, with the whiskers at 2nd and 98th percentiles.

where the CDP indicated a liquid water content greater than $0.01 \mathrm{~g} \mathrm{~m}^{-3}$ ). The lower panel shows absolute humidity from the five hygrometers with the Buck being shown in green, GE in blue, TWC in purple, and wvssF and wvssR in black and red, respectively. In this case the TWC is calibrated against the wvssF in cloud free conditions. Although this leaves scope for some absolute error, it enables higher relative accuracy than is achievable using the chilled mirror hygrometers (Abel et al., 2014).

As the aircraft passes from dry to wet conditions, the GE can be seen both to lag behind the other hygrometers and to overshoot substantially. The Buck also overshoots but to a lesser extent, and responds more rapidly, although both chilled mirrors require approximately $50 \mathrm{~s}$ to stabilise. The chilled mirrors can also be seen to lag behind the others when going from moist to dry conditions at $150 \mathrm{~s}$. The overshoot from the chilled mirrors is, however, less than when going from dry to moist. The response of the wvssF can be seen to be slower than the TWC but is clearly more rapid than the other hygrometers.

The behaviour of the wvssR is more interesting. It can be seen to agree well with other hygrometers in cloud free conditions, with a response rate somewhere between those of the wvssF and Buck but, in the presence of liquid water, it appears to report a value closer to the total water content than that of water vapour. The slower response of the wvssR is believed to be due, largely, to the greater wetted area of its inlet.

\subsection{Liquid water}

Figure 6 shows a time series from flight B582 on 11 March 2011, over southern England. The lower panel shows absolute humidity from the wvssF (black), wvssR (red) and a measure of the total water content is shown in green with data from the wvssF humidity + CDP liquid water content (chilled mirror data have been omitted for clarity). The upper panel shows liquid water content (black) and mean volume radius derived from the $\mathrm{CDP}$ (red).

The wvssF is believed to be immune to cloud particles, as illustrated in Fig. 5 and Vance et al. (2011). The wvssF and wvssR agree in cloud free conditions, as expected from the foregoing, but differing behaviours can be seen in the presence of liquid water. In the cloud penetration at $1100 \mathrm{~s}$ the wvssR appears to be reporting total water rather than vapour, agreeing well with the total water estimate. In the previous two penetrations and the initial one, however, although there is clearly some susceptibility to liquid water, wvssR only matches the TWC values at the smaller end of the size spectrum. It should be noted, however, that the mean volume radius at which the departure from the total water values occur varies. Vance et al. (2011) shows examples of susceptibility 


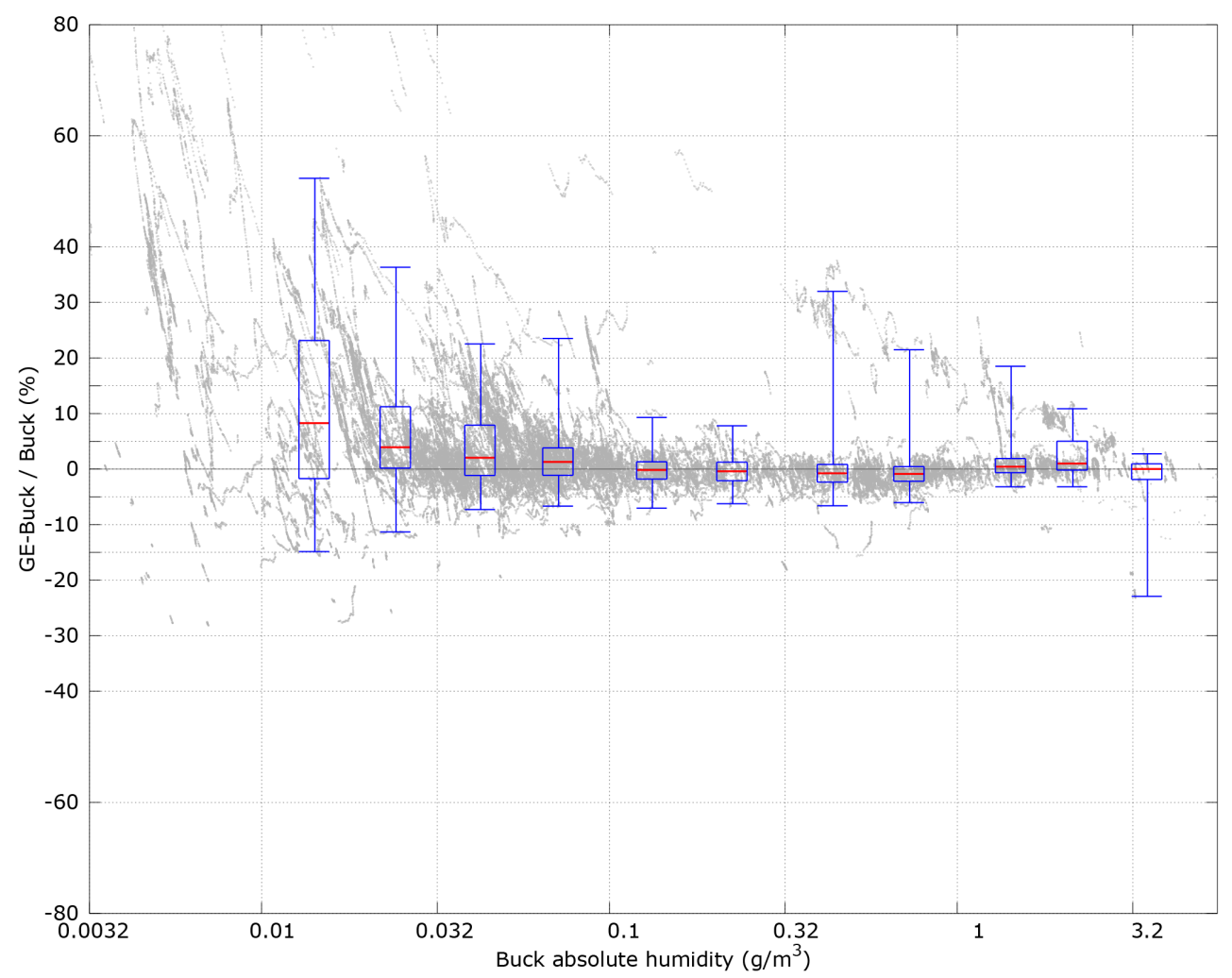

Figure 3. GE minus Buck in cloud free conditions. Boxes indicate binned quartiles, with the whiskers at 2nd and 98th percentiles.

to liquid droplets of around $20 \mu \mathrm{m}$ radius but no susceptibility to cloud with a modal radius of $8 \mu \mathrm{m}$. It is therefore not possible to draw conclusions about the importance of droplet size from these data, but it is clear that the wvssR is unreliable in liquid cloud as it can ingest and evaporate some liquid cloud droplets whereas the wvssF does not. This is, perhaps, not surprising as it has been noted that Rosemount housings used for temperature measurements are also susceptible to errors due to wetting in liquid cloud (e.g. Lawson, 1990; Lenschow, 1974).

\subsection{Ice clouds}

Figure 7 shows a time series from flight B672 on 30 January 2012, over the Northwest Approaches and North Channel. The aircraft performed a Lagrangian descent in a "racetrack" pattern throughout the depth of cirrus cloud over a period of hours; the portion of the descent presented here is also discussed by Abel et al. (2014). The upper panel shows absolute humidity from three instruments: wvssF (black), wvssR (red) and TWC (purple), which has been calibrated against the wvssR in cloud free conditions; in the interests of clarity, the Buck and GE have been omitted as they were clearly not stable during this period. Four "steps" in the humidity data can be seen, corresponding to four race-tracks at different altitudes. Although small offsets (removed for the bulk inter- comparison, above) are apparent between the two WVSS-II and the two chilled mirrors, they can be seen to report the same basic conditions. The TWC is, of course, reporting humidity arising from all phases. The large increases in total water correspond to the aircraft passing through fall streaks embedded in the cirrus. In these regions the density of ice particles is significantly higher than the background. This lower background ice concentration is evident as "noise" on the TWC trace between the fall streaks. Although the situation is substantially less conclusive than in the case of liquid water, there is some suggestion that ice particles may be evaporating in the wvssR and producing enhancements in some of the fall streaks.

The lower panel shows a comparison of wvssR (red) and wvssF (grey) to the Buck during this period in terms of absolute humidity, analogous to the plots in Figs. 2-4. As previously noted, the offset removed for the bulk comparison is apparent, as is the gradual over-reading of the wvssF but no differences attributable to the presence of ice are readily apparent.

\section{Discussion}

Analysis of data from around 100 research flights spanning a wide range of atmospheric conditions shows that, within the limits of this study, the wvssR agrees (well within IQR) with 


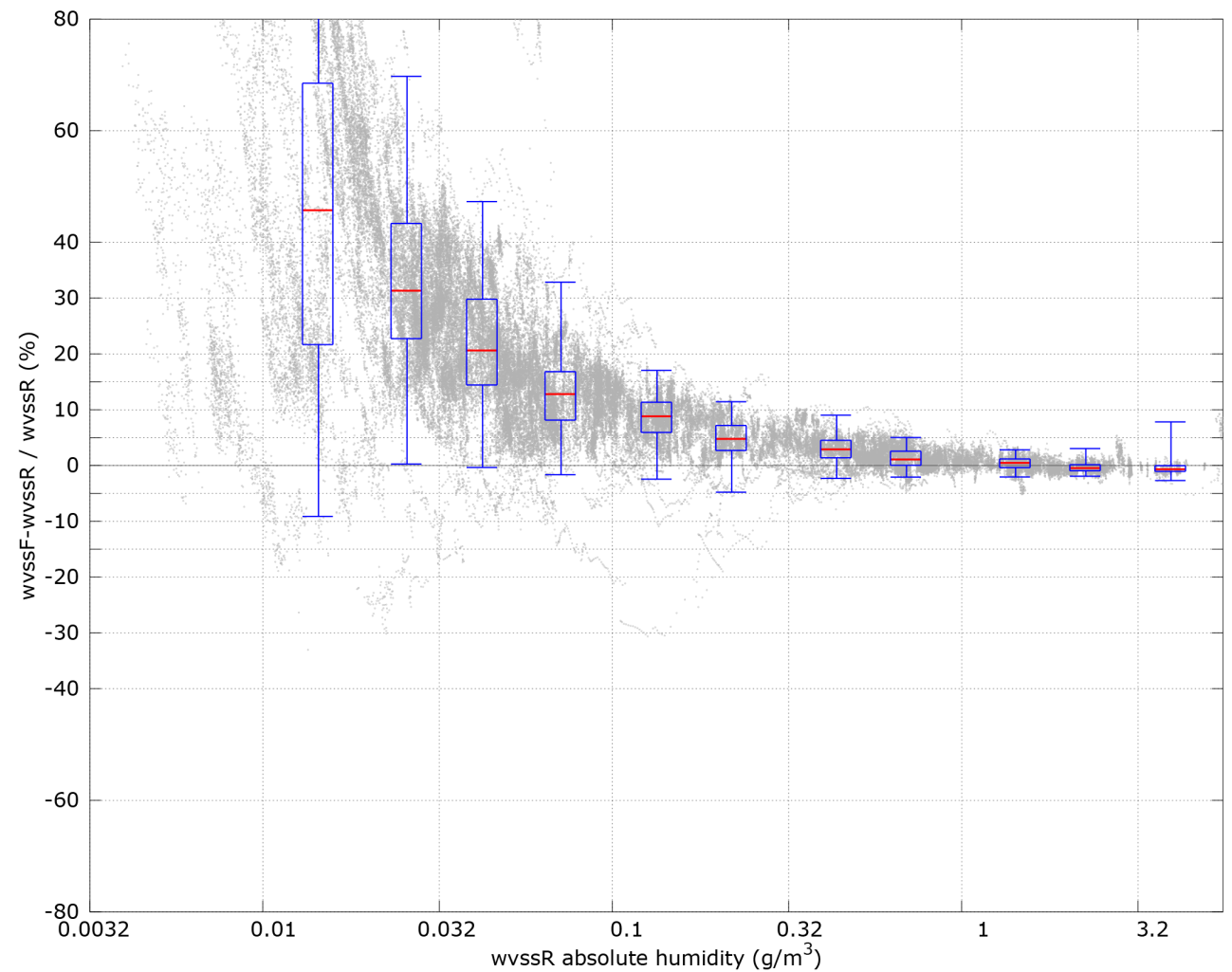

Figure 4. wvssF minus wvssR in cloud free conditions. Boxes indicate binned quartiles, with the whiskers at 2nd and 98th percentiles.

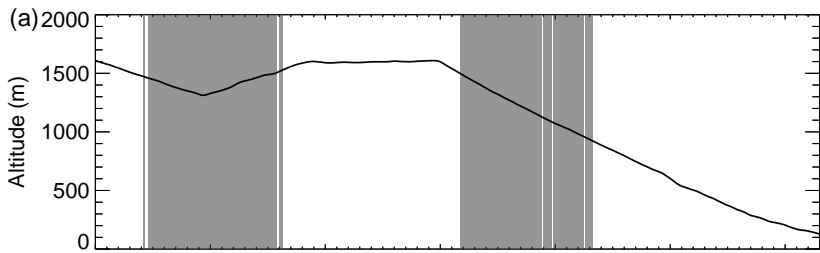

(b)

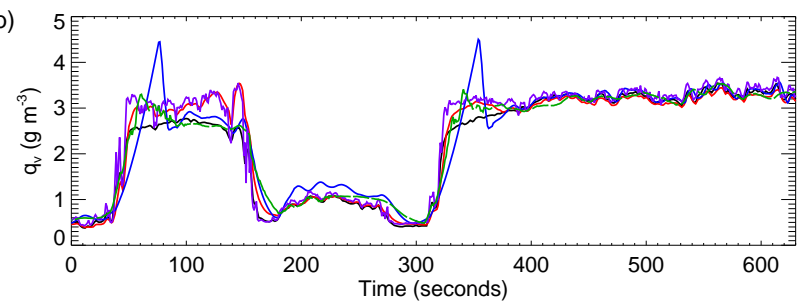

Figure 5. Time series from flight B668 when the aircraft was profiling in and out of a moist boundary layer with much drier air above. The top panel shows the aircraft altitude with periods in cloud shaded in grey. The lower panel shows absolute humidity from the Buck (green), GE (blue), TWC (purple), wvssF (black) and wvssR (red).

the GE and the Buck in cloud free conditions. The wvssF is found to over-read, progressively, in drier conditions, with the discrepancy between it and the wvssR being outside the IQR below $0.5 \mathrm{~g} \mathrm{~m}^{-3}$ and outside the $2 \mathrm{nd} / 98$ th percentile be-

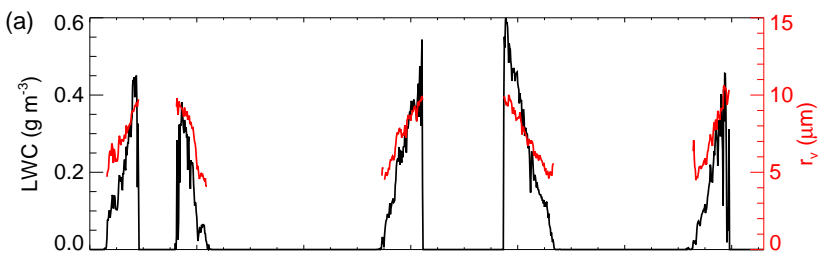

(b)

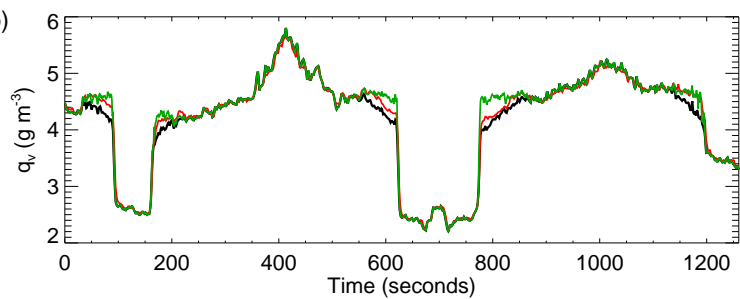

Figure 6. Time series from flight B582 showing penetrations of liquid cloud (chilled mirror data omitted for clarity). Lower panel shows absolute humidity from the wvssF (black), wvssR (red) and wvssF + CDP liquid water content (green). Upper panel shows liquid water content (black) and mean volume radius (red) derived from the CDP.

low $0.03 \mathrm{~g} \mathrm{~m}^{-3}$. Although care has been taken to reject from the comparison periods where the chilled mirror hygrometers were unstable, the difficulties in doing this objectively mean that some data from such periods remain in the com- 

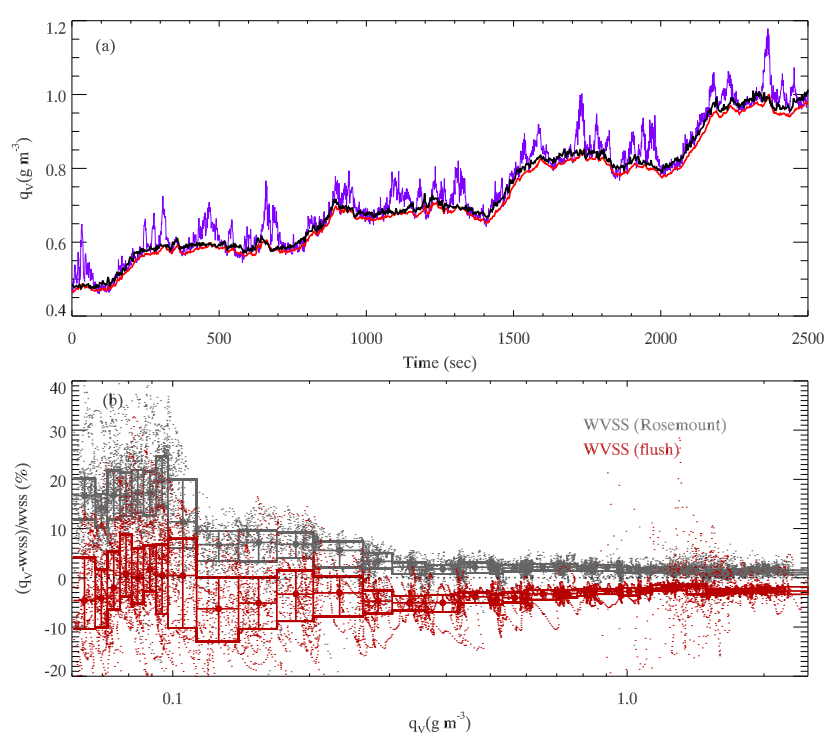

Figure 7. Time series from flight B672 showing part of a Lagrangian, "race-track" pattern descent through cirrus cloud with embedded fall streaks. Upper panel shows absolute humidity from wvssF (black), wvssR (red) and TWC (purple). Lower panel shows a comparison of wvssR (red) and wvssF (grey) to the Buck during this flight in terms of absolute humidity with boxes indicating upper and lower quartiles.

parison, and this hampers the assessment, particularly in very dry conditions.

Unpublished, preliminary data from AquaVIT 2 suggest that although the WVSS-II may be able to measure humidities as low as $0.6 \mathrm{mg} \mathrm{m}^{-3}$ it is likely to over-read substantially below $15 \mathrm{mg} \mathrm{m}^{-3}$; there may be evidence to support this from the airborne data presented but uncertainties in the other instruments leave this inconclusive. Preliminary AquaVIT $_{2}$ data also suggest that the wvssR may under read by about $3 \%$ for humidities greater than $0.01 \mathrm{~g} \mathrm{~m}^{-3}$ and over-read substantially below this value; there may be some support of this in the data presented here. Although the Buck and GE show good agreement in more humid conditions, the GE appears to over-read in drier conditions, supporting FAAM's suspicion of a positive bias when mirror temperatures are below $250 \mathrm{~K}$ (FAAM, 2014b).

In order to facilitate comparison of the relative performance of the hygrometers, calibration offsets between the instruments have been estimated and removed, absolute accuracies being better assessed in the laboratory than in the field. Whilst the possibility of calibration drift during the test period is acknowledged, the nature of the flying makes quantification of this problematic and so zero drift has been assumed. The results presented here, therefore, refer to relative performance only, rather than absolute.

The wvssF shows very rapid response to large changes in humidity, only slightly slower than the TWC. Although the wvssR is noticeably slower to respond than the wvssF, it is substantially faster than the two chilled mirrors, and neither WVSS-II suffered from the long stabilisation periods often required by the chilled mirror instruments. Although the wvssF appears to be immune to liquid cloud, the wvssR is not, and may, under certain conditions, report a value closer to the total water content than the vapour content. It has not been possible, from these data, to define these specific condition, and in order to make use of wvssR data in liquid cloud further investigation would be required. Alternatively, the provision of an inlet capable of measuring dry conditions, as can the Rosemount inlet, but showing the flush inlet's immunity to liquid, could usefully be investigated. Similarly, the wvssF appears to be insensitive to ice cloud whereas data suggest that the wvssR may be sensitive to it, although the situation is less clear for ice than liquid water, and further work would be required to properly characterise its performance under these conditions. Further work is required to characterise biases and offsets between the WVSS-II and the chilled mirror hygrometers, and between the two WVSS-II.

Acknowledgements. The authors wish to acknowledge the assistance of Axel Hoff (DWD), Denis Smorgon (KIT), Bryce Ford (SpectraSensors), FAAM, Directflight Ltd., and Avalon Aero for their assistance in the collection and analysis of presented here, and DWD for provision of two WVSS-II.

Edited by: S. Malinowski

\section{References}

Abel, S. J., Cotton, R. J., Barrett, P. A., and Vance, A. K.: A comparison of ice water content measurement techniques on the FAAM BAe-146 aircraft, Atmos. Meas. Tech., 7, 3007-3022, doi:10.5194/amt-7-3007-2014, 2014.

Baker, R., Curtis, R., Helms, D., Homans, A., and Ford, B.: Studies of the effectiveness of the water vapor sensing system, WVSS-II, in supporting airline operations and improved air traffic capacity, 91st American Meteorological Society Annual Meeting, Seattle, WA, 22-27 January 2011.

Bedka, S., Petersen, R., Feltz, W., and Olson, E.: Evaluation of the WVSS-II Sensor Using Co-located In-situ and Remotely Sensed Observations, 7th International Symposium on Tropospheric Profiling: Needs and Technologies, Boulder, CO, 11-17 June 2006, available at: http://www.eol.ucar.edu/istp2006/pdf/5. 03A_Bedka_S.pdf (last access: 16 December 2014), 2006.

Brown, P. R. A. and Francis, P. N.: Improved measurement of the ice water content in cirrus using a total-water probe, J. Atmos. Ocean. Tech., 12, 410-414, 1995.

FAAM: Buck CR2, available at: http://www.faam.ac.uk/index.php/ science-instruments/humidity/112-cr2 (last access: 16 December 2014), 2014a.

FAAM: General Eastern, available at: http://www.faam.ac.uk/ index.php/science-instruments/humidity/111-general-eastern (last access: 16 December 2014), 2014b.

Fleming, R. J. and May, R. D.: The 2nd Generation Water Vapor Sensing System and Benefits of Its Use on Commercial Air- 
craft for Air Carriers and Society, UCAR, Boulder, CO, available at: https://www.eol.ucar.edu/system/files/spectrasensors.pdf (last access: 16 December 2014), 2004.

General Eastern Instruments: Model 1011B Dew Point Hygrometer for Aircraft Preliminary Operating Manual, available at: http://www.faam.ac.uk/index.php/component/docman/ doc_download/37-ge-manual (last access: 16 December 2014), 1987.

Hoff A.: WVSS-II Assessment at the DWD, Deutscher Wetterdienst, Offenbach am Main, Germany, available at: http://amdar. noaa.gov/docs/WVSS-II_Assessment_DWD.pdf (last access: 16 December 2014), 2009.

Hoff, A.: Advancements in the AMDAR Humidity Sensing, Commission for Instruments and Methods of Observations Technical Conference on Meteorological and Environmental Instruments and Methods of Observation (CIMOTECO) 30 August-8 September 2010, Helsinki, Finland, available at: http://amdar.noaa.gov/docs/TECO2010_AMDAR_WV_ Helms-Hoff_6.pdf (last access: 16 December 2014), 2010.

Lance, S., Brock, C. A., Rogers, D., and Gordon, J. A.: Water droplet calibration of the Cloud Droplet Probe (CDP) and inflight performance in liquid, ice and mixed-phase clouds during ARCPAC, Atmos. Meas. Tech., 3, 1683-1706, doi:10.5194/amt3-1683-2010, 2010.

Lawson, R. P. and Cooper, W. A.: Performance of Some Airborne Thermometers in Clouds, J. Atmos. Ocean. Tech., 7, 480-494, doi:10.1175/1520-0426(1990)007<0480:POSATI>2.0.CO;2, 1990.

Lenschow, D. H. and Pennell, W. T.: On the Measurement of In-Cloud and Wet-Bulb Temperatures from an Aircraft, Mon. Weather Rev., 102, 447-454, doi:10.1175/15200493(1974)102<0447:OTMOIC>2.0.CO;2, 1974.

Mamrosh, R., Gillis, J., Petersen, R., and Baker, R.: A Comparison of WVSS-II and NWS Radiosonde Temperature and Moisture Data, 10th Symposium on Integrated Observing and Assimilation Systems for the Atmosphere, Oceans, and Land Surface (IOAS-AOLS), Atlanta, GA, 28 January-2 February 2006, available at: https://ams.confex.com/ams/pdfpapers/104889.pdf (last access: 16 December 2014), 2006.
Moninger, W. R., Benjamin, S. G., Dévényi1, D., Jamison, B. D., Schwartz, B. E., Smith, T. L., and Szoke, E.: AMDAR Optimization Studies at the Earth System Research Laboratory / Global Systems Division, 10th Symposium on Integrated Observing and Assimilation Systems for the Atmosphere, Oceans, and Land Surface (IOAS-AOLS), Atlanta, GA, 28 January-2 February 2006, available at: https://ams.confex.com/ams/pdfpapers/ 104488.pdf (last access: 16 December 2014), 2006.

Nicholls, S., Leighton, J., and Barke,r R.: A New Fast Response Instrument for Measuring Total Water Content from Aircraft, J. Atmos. Ocean. Tech., 7, 706-718, 1990.

Petersen, R. A., Feltz, W., Bedka, S., and Olson, E.: Results of the November 2006 WVSS-II - Rawinsonde Intercomparison Study, report for NOAA/NWS/OST, University of Wisconsin, Madison, WI, available at: http://amdar.noaa.gov/docs/ UW_WVSS-II_Nov2006_Assessment_FINAL.pdf (last access: 16 December 2014), 2008.

Petersen, R., Cronce, L., Olson, E., Feltz, W., Helms, D., and Baker, R.: WVSS-II Moisture Observations - A Tool for Validating and Monitoring Satellite Moisture Data, EUMETSAT Meteorological Satellite Conference, Córdoba, Spain, 20-24 September 2010, available at: http://amdar.noaa.gov/docs/Petersen presentation.pdf (last access: 16 December 2014), 2010.

Vance, A. K., Woolley, A., Cotton, R., Turnbull, K., Abel, S., and Harlow, C.: Final Report on the WVSS-II Sensors Fitted to the FAAM BAe 146, report for E-AMDAR programme, Met Office, Exeter, UK, available at: http://www.metoffice.gov.uk/ media/pdf/7/r/WVSS_II_final_2011_Tagged.pdf (last access: 6 February 2015), 2011.

WMO: The AMDAR Observing System, available at: http://www.wmo.int/pages/prog/www/GOS/ABO/AMDAR/ AMDAR_System.html (last access: 16 December 2014), 2014a.

WMO: The Benefits of AMDAR to Meteorology and Aviation, WIGOS Technical Report 2014-1, Version 1, January 2014, available at: https://www.wmo.int/pages/prog/www/GOS/ ABO/AMDAR/publications/Benefit_of_AMDAR_Data_to_ Meteorology_and_Aviation.pdf (last access: 16 December 2014), 2014b. 